\title{
Mentor and Working Environment in Support of Vocational Student Teachers' Professional Development
}

\author{
Erkkilä Raija \\ Oulu University of Applied Sciences, \\ School of Vocational Teacher Education, \\ Finland
}

\begin{abstract}
This study is part of a larger project begun in 2009 to examine vocational student teachers' mentoring experiences during the teaching practice. It was designed and carried out in Finland at the School of Vocational Teacher Education, University of Applied Sciences. The project aims to understand the complexity of mentoring during the teaching practice period. In the first phase of the research project the supervising relationship between a mentor and a mentee during the teaching practice was examined. The empirical data was collected both from mentors and mentees. The current study is the second phase of the project, where the aim is to deeper understand how vocational student teachers' experience being mentored in the teaching practice. The empirical data was collected from vocational student teachers using group discussion. In the analyses, two categories were found: student teachers' self-direction and communal experiences. These two factors are significant in a student teacher's professional development and should be considered during the supervision of teaching practice. The results indicate that one essential prerequisite for successful teaching practice includes the student teachers' self-direction, which is connected to positive and constructive feedback from a mentor. A supportive educational environment was also positively associated with the student teachers' community competence and professional development.
\end{abstract}

\section{Introduction}

There is a growing interest among researchers in the professional development of vocational student teachers. Studies show that learning to be a teacher is a long and dynamic process that begins early in the process of education. The research has deepened the understanding, how teacher's identity develops, which kind of phases teachers confront on their career, and how their pedagogical and practical thinking develop. $[1,2,3$.] The research has also contextualized the knowledge gained in various educational environments showing that pedagogical

\author{
Perunka Sirpa \\ Oulu University of Applied Sciences, \\ School of Vocational Teacher Education, \\ Finland
}

and professional knowledge are constructed through an active interaction with the context of individual, social and cultural processes and variances with time $[4,5,6]$.

Research has revealed that the teaching practice period is one of the most critical phases in professional development, and the guidance provided during this time plays a very important role in the whole of teacher education [7,8]. Teaching practice guidance has a decisive impact on the development of the teacher's professional identity, which is critical to future work because the teacher's job includes continuous intellectual, social and emotional interaction with students, colleagues, parents and work life [9].

In the research literature, there are numerous concepts and definitions used to describe teacher training guidance, such as mentoring. The terms 'cooperating teacher' and 'supervisor mentor' are also referred to frequently. In the field of teacher education, this diversity of terms is rooted in three sources: 1) various social positions from which supervisory activities can be undertaken, 2) the changed role expectations of mentor teachers and 3 ) diversity of terms used to refer to mentoring dialogues [10]. The common denominator of these definitions is that teacher training guidance is defined as the experienced teacher supervising the beginning teacher. The main goal is to support the development of the student teacher into an autonomous person [11]. In this study, the term 'mentor' implies an equal relationship between the mentor and student teacher. This research revealed that the mentors and mentees emphasize the importance of an equal and confidential atmosphere in the mentoring relationship [12].

One important task of the mentor is to encourage the student teacher to reflect on his or her actions. Through reflection, a teacher consciously examines personal attitudes, values and knowledge. The teacher is able to come to a conclusion concerning the relevance of beliefs or supposed knowledge. Reflection has been recognised as an important factor in renewing adult learning, because it fosters change; and the central role of reflection in a 
teacher's professional development has been established as valuable in the education field. By moving from reflection to critical reflection, teachers move from analysing a single aspect of a lesson to considering the ethical, social and political implications of teaching practice $[2,13]$. Teacher training in many countries also emphasizes selfreflection. Kelchtermans and Hamilton [14] point out that the act of reflection should not be approached too narrowly, and that reflection should concern the values, norms, broad ethical and political aspects of teaching as well as the technical aspects.

This article focuses on vocational student teachers' mentoring experiences during the teaching practice. Vocational teachers are second-career teachers who have experience with working life and life in general. A vocational teacher already has a professional identity constructed through working in the particular occupation. Becoming a vocational teacher is a process of building a double identity. Lee [15], in reference to Novak and Knowles, claimed that second-career teachers need mentoring and adjustment time the same as other novice teachers. So, mentoring is necessary during the teaching practice and can play an important role in professional development. This present study, then, asks the question: 'What is the significance of mentoring in the vocational student teachers' professional development?'

\section{Context of the study}

Industry, educational institutes and society at large continually change and renew the work and work-related needs of a vocational teacher. A modern teacher is expected to possess the extensive knowledge, versatility and ability necessary to react immediately to changing work situations. The vocational and higher education teacher is not only expected to be an expert in his or her own field but to be tutors and developers of new work-related practices. The demands are high: not only do these educators need professional expertise, willingness to do research, ability to innovate and passion for developing new solutions but also international networking skills. The teacher must also be responsibility for his or her work, maintain workrelated ethical principles and mentor the students' ethical development [16].

The path leading to vocational teacherhood differs for example from the path of the primary or secondary school teacher. In the case of Finland, the general entrance requirement for vocational teacher education is a master's degree or the highest vocational degree in the major subject with three years of work experience in the field. Often, a vocational student teacher is embarking on a second or even third career. These teachers have deep knowledge in their respective fields and have often completed the master's or doctoral thesis. One result of the high entrance demands is that the average age of the teacher student is 40 years. To become a vocational teacher means combining two fields of expertise; expertise in a specific field and in education.

\subsection{The first phase of the research project}

This mentoring project began in 2009 and was designed and carried out in Finland at the School of Vocational Teacher Education, a unit of the Oulu University of Applied Sciences. The first phase was completed between 2009 and 2012. The study clearly demonstrated that the mentoring process was perceived as rewarding. Both the mentors and mentees emphasized the importance of an equal and confidential atmosphere. Also, the mentoring process was connected to personal and professional growth. For example, the mentors reported that their own subject-based knowledge developed in the course of mentoring. Mentees claimed that mentoring inspired them to analyse their pedagogical behaviours [12]. The results have encouraged us to develop mentoring more towards dialogicality and to pay attention to mentor education. The results also revealed the importance of collecting new data from vocational student teachers, which became the foundation of the second phase of this present project. The aim of this research was to understand vocational student teachers' mentoring experiences in the teaching practice.

\subsection{Teaching practice as part of teachers' pedagogical studies}

The School of Vocational Teacher Education offers pedagogical studies of 60 ECTS. The curriculum is based on the work and development of a vocational teacher and the teacher's professional skills. The objective of the curriculum, in content and form, is to promote the development of a teacher as an expert in pedagogy [12]. Teaching practice is an important part of pedagogical studies. Throughout the teaching practice period, the students may use the skills learned in the previous vocational pedagogical studies and may work mutually with other students in the work community. In the curriculum, the teaching practice period is 13 ECTS (Figure 1). 
Teachers pedagogical studies (60 ECTS), study programme:

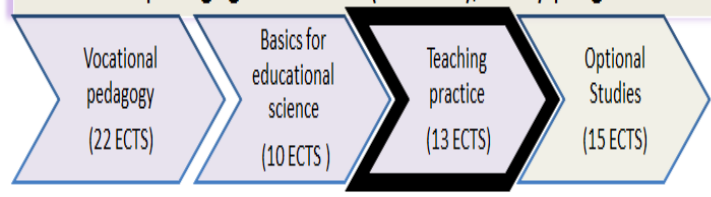

Figure 1. Teacher's pedagogical studies

During the pedagogical studies, a student teacher gains insight into the teaching profession through teaching practice period. The main targets of the practice are:

- to provide an opportunity to apply pedagogical knowledge and skills in practice

- to enable the student teacher to design, carry out and evaluate the teaching methods

- to help the student teacher understand his/her role in the whole of the profession

To succeed in achieving the targets, a student teacher is provided with a mentor during the practice period.

In this study, a mentor is the teaching practice supervisor who has been chosen among the teachers at the institution involved to support the practicing student teacher. The mentor works as a full-time teacher, and is a qualified with many years of teaching experience. The mentor shares a number of lessons or other teaching projects with the student teacher, who is responsible for the agreed-upon unit of lessons. The mentor teacher supports the student teacher in planning, implementation and student evaluations. The role of the mentor is

- to assist the student teacher in the interpretation of student behaviours and to help him/her discover how to promote and guide the students' learning processes.

- to familiarize the student teacher with the culture, habits and learning environments of the school.

- to familiarize the student teacher with the student group's learning and working processes.

- to support the planning and implementation and approve a core plan for the module that the student teacher will teach.

- to give feedback and a developmental discussion after each teaching lessons and at the end of teaching practice.

- to compose a written evaluation at the end of teaching practice.

\section{Method}

This is a qualitative study, whose aim is to describe and understand a phenomenon; the study does not seek to provide causal explanations. The interest of the study is to understand the experiences of student teachers. A qualitative analysis was used to uncover the themes and subcategories that emerged from the text [17].

In order to achieve authentic descriptions of informants' experiences, group discussion was used for data collection. The group discussion was designed to explore student teachers' experiences concerning the supervision of the teaching practice. The group discussion resembled the focus group method. Kitzinger [18] defines the focus group method as a form of group interviewing that capitalises on communication between research participants to generate data. The focus group method is an efficient way to collect data from several people simultaneously. There are also more significant benefits to using this method. It enables group processes to emerge, which can help the student teacher explore his or her views in ways that would be less accessible in a one-on-one interview. Participants are also able to explore issues of personal importance using their own vocabularies, generating their own questions and pursuing their own priorities. The group process, however, is not only about consensus. Differences between individuals within the group are equally important $[17,18]$.

\subsection{Data collection}

The research participants consisted of 21 vocational student teachers, including 12 female and 9 male student teachers representing different occupational fields. The amount of prior teaching experience varied. Some participants had been working as teachers for several years, and some had no experience at all. When the data was gathered, the student teachers had completed their teaching practices. They had all practiced in different vocational schools or universities of applied sciences. Each student teacher had his or her own mentor.

To generate the most authentic data, the researchers were not present during the group discussions. Though the researchers were not able to ensure that the provided themes were discussed, it was considered more important that the researchers couldn't suggest any topics or lead the discussion anyhow. It was considered important that student teachers had a possibility to tell their experiences as widely as they wanted without the influence of the researchers.

The data was collected from five group discussions held from 2012 to 2013. The group discussions were organised by the researchers. Each group included four to five student teachers. The participation to the group discussion was voluntary. Group discussions took place in a seminar, which is part of the student teachers' pedagogical studies and 
were designed to reflect the teaching practice. The seminars were organized after teaching practice. The two researchers gathered data from their respective seminars. The aim of the group discussions was to explore the student teachers' experiences during the supervision of teaching practice.

Each group was given written instructions. The participants were advised to discuss the themes freely but to be sure all the themes were part of the discourse. The aim of the study was explained and the six open questions concerning guidance during the teaching practice were provided. The questions were:

- How did you experience the guidance during your teaching practice?

- What was the significance of mentoring for your professional development?

- What kind of needs did you have towards mentoring, and how did the mentoring meet your expectations?

- What was the best experience in mentoring?

- Which kind of role did you have in mentoring?

- What else would you like to tell about mentoring?

Each group recorded the discussion, which lasted from 40 to 60 minutes. Some discussions were informal, while some were structured, approaching the questions in order. All the groups discussed all the themes and questions.

\subsection{Data analysis}

The group discussions were transcribed by the researchers. For the data analyses, the researchers first explored their own data. After reading the material carefully, the researchers investigated and discussed the emerging themes. The data were subjected to cross analysis by both researchers, and common themes were extracted.

Step-by-step data analysis:

1) Discussions from the seminars were transcribed by one researcher

2) First analysis of the data was made by the same researcher

3) Joint discussion was held to compare the themes

4) Similar themes were identified for further analysis and named

5) Cross analysis of data was conducted

6) Final themes were extracted.

\section{Results}

\subsection{Individual guidance needs}

This research indicated that guidance needs varied among student teachers. Each student teacher was at a different stage in the journey to become a competent teacher, and therefore each required personalized guidance. For example, one student teacher described the experience of being in front of the class for the very first time:

'I turned to the mentor many times during the lesson. I asked her opinion when I felt that I lost the point in my teaching.'

This kind of need is typical for a student teacher, who has no previous or only little experience in teaching.

Also, Hennissen et al. [19] point out that beginning teachers need support in the form of task assistance to help them refine their teaching skills. This type of support includes the provision of feedback, information and practical advice, and questions and discussion topics concerning teaching. The emphasis is on the practicality of the discussion and advice [19].

For some of the student teachers, the availability of the mentor and the knowledge that the support was continuously available were of prime importance during all phases of the teaching practice. One student teacher said:

'My needs were related to things like planning, implementation and evaluation.'

Another student, who had been working as a teacher for a few years, shared:

'We have been working together with my mentor also before my teaching practice, so we know each other and the ways we both teach. We have discussed a lot. So my mentor was more in the background.'

Regardless of a student teachers' previous teaching experience, there was one common element that connected them: the student teachers sought help on their own and turned to their mentors when they needed guidance. It seems that a student teacher's self-directive and the ability to seek help when it is needed is an essential prerequisite for a successful teaching practice. One characteristic of true selfdirectiveness is that guidance is sought at the right moment.

A teacher's professional growth is a long process, and it can be supported by a successful mentoring relationship right from the start. However, it is crucial to understand [20] that there is no single mentoring approach that will work in the same way for every mentee in every context. Thus, the development of a diverse and individualized mentoring style that incorporates the mentees' personal needs is an important challenge for mentors.

\subsection{Communal experience}

Another interesting result concerns the educational institution's working environment. In this research, working environment is defined as the social, pedagogical, developmental and physical contexts of the institution in which teaching and learning occur [7]. The student teachers' experiences 
varied based on this environment. Some student teachers felt they had been duly supported by the school:

'I think that I got more ideas from the other teachers than my mentor; I really got into the work community.'

Another student teacher clarified the experience in a very concrete way:

'It was the moments outside of the lessons. We went to sit with other teachers and it was the discussions by coffee breaks and at lunch. It was a very smooth way to have access to the discussions. With the help of a mentor. It would have been very easy to continue at that school as a teacher.'

The following discussion between two student teachers illustrates, how they compared their experiences in group discussions and noticed that there were big differences between educational environments. The differences came out as attitudes that the environment reflected.

- I had the feeling that the work community was against my teaching practice. The heads/leaders weren't interested at all.

- In our school, they were interested in my teaching practice. My boss and the others encourage me and said 'good, good'.

- I think that attitude is important. If they only had clapped me on the shoulder and said 'keep going', but they didn't do even that.

The discussion above also illustrates that not every student teachers felt supported by the management. Some reported that the actions of the other teachers and the management, in fact, had hindered their successful teaching practice.

When considering the success of the student teacher and the teaching practice process as a whole, the attitudes emanating from the educational environment and the people working in it have significant impact. Huang and Waxman [7] point out that the school environment is where the student teacher engages in practical matters. If he or she feels accepted into this environment, it will strengthen the commitment to the teaching profession.

The student teachers expected their mentors to introduce them to the school environment broadly. Again, self-directed student teachers were able to do this independently:

- I think I learned more from other teachers than from my mentor. I got into the staff.

- It was an important act from your mentor that he took the responsibility and helped you with that.

- No, the mentor didn't do that. I took the responsibility myself.

In this present study, the significance of a supportive environment was apparent. A supportive atmosphere and open access to the school culture facilitated student teacher's actions and performance. Furthermore, this study showed the importance of the student teacher's active role in the environment. The self-directive of a student teacher manifested in the ability to seek appropriate guidance from the appointed mentor as well as other teachers in the school.

\section{Reflection of results}

These examples and other findings in the data demonstrate how important it is for a mentor to understand the situation and the background of a student teacher. A mentor should be sensitive to the student teacher's needs and be able to offer professional guidance at the right moment, and a mentor should help the student teacher concentrate on the most relevant issues. Some student teachers may ask simple questions on how to organise the lesson and some may require help to reflect on more basic values in teaching and learning. Also Aaltonen [4] points out the same kind of notion and claims that understanding teaching in context and rebuilding pedagogical thinking requires many kinds of reflection.

In the research literature, there are various terms denoting a mentoring process in the field of teacher education. Booth [21] presents three areas where student teachers emphasised characteristics of successful mentoring. It is interesting to compare his classification to the findings of ongoing study. First, Booth describes general support, which includes accessibility of the mentor, sympathetic and positive support and time spent on mentoring. The quality of general support in a good mentor was also a theme in this study and was clearly appreciated among the participants.

Booth's second area is the extent to which mentors aided students' professional development. Students valued mentors who treated them as professionals and adopted a less directive counselling style. They also appreciated the opportunity to set part of the mentor-student discussion agenda. Comparing Booth's classification to the findings of this study, these features were especially appreciated by those student teachers who had worked for several years in a teaching profession. These student teachers had passed the 'survival' period of professional development and needed support in deeper reflection. The difference to the Booth's third area is clear, where emphasis is on the practicality of the mentor-student discussion and the advice offered therein $[19,21]$. This kind of mentoring is typically hoped in the beginning of teaching practice.

An interesting phenomenon emerged in conjunction with the role of the school community in the teaching practice. The active or self-directed student teachers widely sought guidance and support. 
For them, it was possible to have various reflective discussions, which was critical to these student teachers' development.

Much of the research in the last decade has focused on the importance of communities of practice in teacher learning, but the emphasis has been on individual teacher reflection in many cases. There are consequences of focusing on individual teacher reflection and the lack of attention of the social context of teaching and teacher development. One of these consequences has been that teachers might come to see their problems as their own [22]. According to Dobber et al. [23], the possibility of developing so-called community competence, that is, the ability to establish, maintain and develop relationships with other professionals as a basis for a professional learning and working culture in the school, enables beginning teachers to work as socially engaged professionals once they enter the profession.

The results from this study show that, regardless of a student teacher's needs and background, his or her self-confidence as a teacher is connected to positive and constructive feedback from a mentor. A student teacher's perception of belonging to the school community was positively associated with professional development as vocational teachers.

\section{Conclusion}

The student teachers' self-directive and communal experience are intertwined, with selfdirective influencing significantly to the amount and quality of the guidance that the student teacher receives. Those, who were self-directive sought guidance extensively when it was appropriate, while the others remained even in an unsatisfactory situation. This result suggested that the way the relationship between the mentor and student teacher was experienced was of great importance. According to previous work in this project [12], the successful mentoring relationship was defined equally and dialogically by both mentors and student teachers. Also, the desire for a confidential atmosphere in mentoring was expressed. This enabled the partners to construct a new understanding of the realities of teaching as well as personal and professional growth.

At its best, mentoring is a two-way learning process where the mentee takes also a responsibility for his or her personal and professional development and career advancement. It is aimed towards making the mentee self-resourceful. This view of mentoring emphasises the experience gap rather than the status gap [24]. Though the student teacher may be less experienced than the mentor in the teaching profession, he or she brings competence in other important areas related to the past professional life. Student teachers' trust and confidence in this personal competence should be reinforced during teacher education.

Furthermore, it is crucial that teacher educators co-operate with mentors and encourage them to approach the mentor role in a broad way concerning the institution's working environment. This includes especially helping the student teacher foster relationships with other teachers and school staff.

Teaching practice is arguably the most anticipated period among student teachers, and it is the most rewarding period during pedagogical studies. Good experiences during these studies correlate with a proficient mentoring experience during the practice. Good mentoring involves the right kind of guidance at the right time.

\section{References}

[1] Elbaz-Luwisch, F. (2011) "Teaching and marginality: Lessons from teachers' life stories", In: Anneli Lauriala, Raimo Rajala, Heli Ruokamo and Outi Ylitapio-Mäntylä (eds.) Navigating in educational contexts. Identities and cultures in dialogue. Rotterdam: Sense Publishers, pp. 1729.

[2] Feiman-Nemser, S. (2001) "From preparation to practice: Designing a continuum to strengthen and sustain teaching", Teachers College Record, 103(6), pp. 10131055.

[3] Kelchtermans, G. (1993) "Getting the story, understanding the lives: From career stories to teacher's professional development", Teaching and Teacher Education, 9(5/6), pp. 443-456.

[4] Aaltonen, K. (2013) 'The teacher as a pedagogical thinker". In: Katri Aaltonen, Annika Isacsson, Jari Laukia \& Liisa Vanhanen-Nuutinen (eds.) Practical skills education and development -Vocational education and training in Finland. Vantaa: Haaga-Helia University of Applied Sciences, pp. 77-94.

[5] Nissilä, S-P. (2006) "Dynamic dialogue in learning and teaching", Academic Dissertation. University of Tampere. Acta Universitatis Tamperensis.

[6] Saunders, R. (2012) "Assessment of professional development for teachers in the vocational education and training sector: An examination of the concerns based adoption model", Australian Journal of Education, Vol. 56,2 , pp. 182-204.

[7] Huang, S-Y \& Waxman, H. (2009) "The association of school environment to student teachers' satisfaction and teaching commitment", Teaching and Teacher Education (25), pp. 235-243.

[8] Gibbs, G. \& Coffey, M. (2004) 'The impact of training 
of university teachers on their teaching skills, their approach to teaching and the approach to learning of their students", Active Learning in Higher Education, 5, pp. 87100 .

[9] Jyrhämä, R. \& Syrjäläinen, E. (2009) "Ohjaussuhde, ohjaajan roolit ja pedagoginen ajattelu opetusharjoittelussa" [Mentoring relationship, the roles of a mentor and a pedagogical thinking in teacher practice], Kasvatus 49(5), pp. 417-431.

[10] Hennissen, P., Crasborn, F., Brouwer, N., Korthagen, F. \& Bergen, T. (2008) "Mapping mentor teachers' roles in mentoring dialogues", Educational Research Review, 3 (2), pp.168-186.

[11] Ianchu-Haddad, D. \& Oplatka, I. (2009) "Mentoring novice teachers: Motives, process, and outcomes from the mentor's point of view", The New Educator, 5, pp. 45-65.

[12] Perunka, S. \& Erkkilä, R. (2012) "Dialogical mentoring in the supervising of student teachers' practice", International Journal for Cross-Disciplinary Subjects in Education (IJCDSE), 3(1), pp. 635-639.

[13] Mezirow, J. (1990) "Fostering critical reflection in adulthood: A guide to transformative and emancipatory learning", Jack Mezirow and associates. San Francisco (Calif.): Jossey-Bass.

[14] Kelchtermans, G. \& Hamilton, M. L. (2004) "The dialectics of passion and theory: Exploring the relation between self-study and emotion", In: J. John Loughran, Mary Lynn Hamilton, Vicki Kubler LaBoskey \& Tom Russel (eds.) International Handbook of Self-Study of Teaching and Teacher Education Practices, Vol. 12. Dordrecht/Boston/London: Kluwer Academic Publishers, pp. 785-810.

[15] Lee, D. (2011) "Changing course: Reflections of Second-Career Teachers", Current Issues in Education. Mary Lou Fulton Teachers College. Arizona State University, Vol. 14, No 2, pp. 1-18.

[16] School of vocational teacher education study guide 2013-2014. Oulu University of applied sciences. http://www.oamk.fi/amok/docs/opiskelijalle/amok_opintoopas_2013-2014_en.pdf_(20 February 2014).

[17] Kvale, S. (2006) "Dominance Through Interviews and Dialogues", Qualitative Inquiry, 12(3), pp. 480-500.

[18] Kitzinger, J. (1995) 'Introducing focus groups' British Medical Journal, 311, pp. 299-302.

[19] Hennissen, P., Crasborn F., Brouwer, N., Korthagen, F. \& Bergen, T., (2011) "Clarifying pre-service teacher perceptions of mentor teachers' developing use of mentoring skills" Teaching and Teacher Education, 27 (6), pp. 1049-1058.

[20] Crasborn, F., Hennissen, P., Brouwer, N., Korthagen, F. \& Bergen, T. (2011) "Exploring a two-dimensional model of mentor teacher roles in mentoring dialogues", Teaching and Teacher Education, 27(2), pp. 320-331.

[21] Booth, M. (1993) "The effectiveness and role of the mentor in school: the students' view", Cambridge Journal of Education, 23(2), pp.185-195.

[22] Zeichner, K. (2008) "A critical analysis of reflection as a goal for teacher education", Educação \& Sociedade, 29 (103) http://www.scielo.br/scielo.php?pid=S0101$73302008000200012 \&$ script $=$ sci_arttext\&tlng=en\%20\%20nt01 (20 February 2014).

[23] Dobber, M., Akkerman, S. F., Verloop, N., Admiraal, W. \& Vermunt, J. D. (2012) "Developing designs for community development in four types of student teacher groups", Learning Environments Research, 15, pp. 279297.

[24] Clutterbuck, D. \& Lane, D. (2004) (eds.) "The situational mentor: An international review of competences and capabilities in mentoring", Gower Publishing Ltd., England. 